\title{
Impact of "e-Commerce Business and boom of online market" on Retailers in Oman
}

\author{
Anwaar Al-Abri \\ Jitendra Pandey
}

\author{
Middle East College \\ Middle East College
}

The Internet plays an important role in our daily life. We use the internet daily almost for every single work. Before e-commerce buying and selling were done without the internet physically in the markets but after the arrival of e-commerce in Oman, our life has become more convenient because of its number of advantages. Online shopping is a part of ecommerce which is done mostly by the users due to e-commerce websites in Oman which allows us to buy and sell the products according to our choice at affordable prices. An Ecommerce website has a lot of impacts on different markets and retailers. In this paper, we will discuss about the different markets and retailers and impacts of e-commerce on them. Electronic commerce is a type of business and can say it is a commercial transaction, It covers many different types of businesses, from consumer based sites, to exchange trading of business and services between corporations. There is much company providing e-commerce services such as eBay, Alibaba express, Shop Site, etc (Khurana . A, 2019). This research talks about Amazon.com Company which is an E-Commerce Company for online shopping based in Seattle, it is one of the biggest companies in Seattle, to sell products online. Jeff Bezos founder of the Amazon Company In 1994, The beginning of Amazon was as an online library and then other elements were added like DVDs, video games, electronics, music, and clothing. Just five years after the start of the Amazon, the company got a great success in generalizing online shopping. Amazon service 137 customers a week, Amazon users are 5x more than e bays, and the user average brings about 189 \$. Also, it has more than 117000 employees around the word. Amazon is interested in providing more easily and batters services that attract more customers. Amazon is the titan of e-commerce payment, data storage, hardware and media, amazon it intervenes in many industries and it is a site of online customer and trader for sale and purchase, the membership in amazon from the united state around 85 million subscribers. The best encapsulation is flywheel of amazon deal ambition that to be customer-obsessed and to overcome the modern e-commercial world, that ambition was clear from early on which keeps Amazon company develop their system and add some tools with the new process through the online system.

Finally, the information system improve the management of Amazon business, decrease the errors either on order details or deliver order, provide a quality work make the order easy and faster low the costs, attract customers, accuracy in registration and record the information and increase the financial income (Kenneth C. Landon, Jane P. Laudon, 2011).

\section{Introduction}

According to the analysis of (2016_2020), E-commerce marketing in Oman presents one percent of total sales. It's still a new market establishment and has many chances to develop in the future. However, e-commerce worldwide marketing it's about going to reach trillion dollars by 2020 . The sales have reached $7.8 \%$ in development nations, e-commerce marketing. In the last decade, China and India's revelation have been widened to e-commerce marketing manufacturing. Since that, many countries have been established.

Moreover, more than twenty percent of the locals made one paying job through the internet in Oman in 2014. However, Oman has the highest mobile phone users in the middle east. Eight 


\section{Journal of Student Research}

Fourth Middle East College Student Research Conference, Muscat, Sultanate of Oman

present of the users has been done shopping online through mobile phones. Most items that have been paying were music and groceries. Still the population purchases product from foreign sites. Smartphones helped way fast in growing e-commerce marketing in Oman and the middle east. Oman and Emerita have the highest smartphone penetration in the reign after Qatar by seventynine percent. The biggest optical in e-commerce marketing is changing the customer's minds. The customers want to pay directly from the store, the customers want to touch and feel the product to sense the quality according to the Mordor intelligence have been done. During electronic shopping first, Oman consumers spend the most money on; clothing, airline, food, travel, Beauty care, medicine, coupons, and hotels. Second, there are factors infect on customers' performance on Oman such as; ease of use, pricing, customer service, and financial inclusion. Third, Majors that including customer buying; inability to get the product closer by touching and seeing, security concerns and impersonal shopping experiences (Kenneth C. Laudon, Carol Traver,2006).

Finally, the studies reveal Oman's situation and inspection of the e-commerce marketing industry. The growth and ways of the market go challenges, changes, inspections, technics use, main companies, upcoming companies, projects and so far. Moreover, In the e-commerce marketing in Oman. The report shows the circumstances of economic scenarios, future expectations and changes impact on the economic politics and the effects of the reasons on growing this sector (E-commerce Market in Oman - Market trend, Growth and Opportunities, 2016 - 2021).

E-commerce Business is wider idea than online shopping, online shopping is only dealing with transaction jobs done by internet and electronic mail and different searching devices. However, ecommerce marketing carries business transactions through different electrons medium like phones, internet, mobile phones, fax machines, ATMs and credit cards. Moreover, online marketing and ecommerce businesses have different features such as online marketing is one of the promoting channels and sealing products. Let's say if you have a pencil you can make advertisements in Google and create memes and post it on FB and Instagram, so people start to like it and your pan soon will come popular in the market like the parker this an example of online marketing. On the other hand, E-commerce marketing selling things through the internet. A customer buys your pen through the website that belongs to you and he makes the payment online through a debit credit card and the pen is delivered to him. This is e-commerce ( Subramanian. R (2016). Product Marketing Associate at Zoho Corporation Oct, 14 ).

The Relationship between online shopping and E-commerce marketing. These to marketing ways have marked its place in the technology world and that depends on any marketing job on shopping through the internet and e-commerce. The success of any business strongly depended on the location of online marketing and e-commerce marketing so it takes work for both of them. Marketing dealing through internet marketing and transaction through the internet. Internet marketing is a part of e-commerce marketing. Moreover, e online and e-commerce marketing available to the customer for around the clock and throughout the week. And it's not a costly job to enforce marketing. Internet marketing connected with various project modals. It comprises of ecommerce business model where goods and services are sold directly to the customer.

For those how to become E-commerce marketing for the last 20 years at this point there are differences between online marketing and e-commerce marketing or business. Yes, before google was the boss!. For the most part, digital marketing is imperative if you are looking to grow your business online. Overall, e-commerce has facets to it that local or blog marketing does not. Everything from development, design, and post-interaction is important in e-commerce for success( Scarpitta, D, 2018).

\section{Related Studies}

According to the statics E-commerce business coming of age in Oman. The e-commerce part was slower because of the limitation on the logistic. Online shoppers feel unhappy because of the 
shipment till now, it's not depending on the drawback of electronic payment and internet connection and they are good things and convenes in Oman. shipment is a big problem as getting an item is just not operative. In the last few years, customers getting items from nearby countries and the USA, some agency and fast mails help us in opening account in the USA and deliver the products through it. The manger of one of the agencies, Oman mail a chive a big step in this road for the last months. The company main goal is to get benefit from e-commerce businesses that provide a chance for small and newly established companies. Moreover, by making a partnership which located in Dubai, Oman posted a new app for delivery serves called Ersal. Which delivers the products to home according to the location of your phones (Nair. V, 2017).

Figure 1. Digital Marketing Services

\section{E-COMMERCE STRATEGY}

\section{Enter your sub headline here}

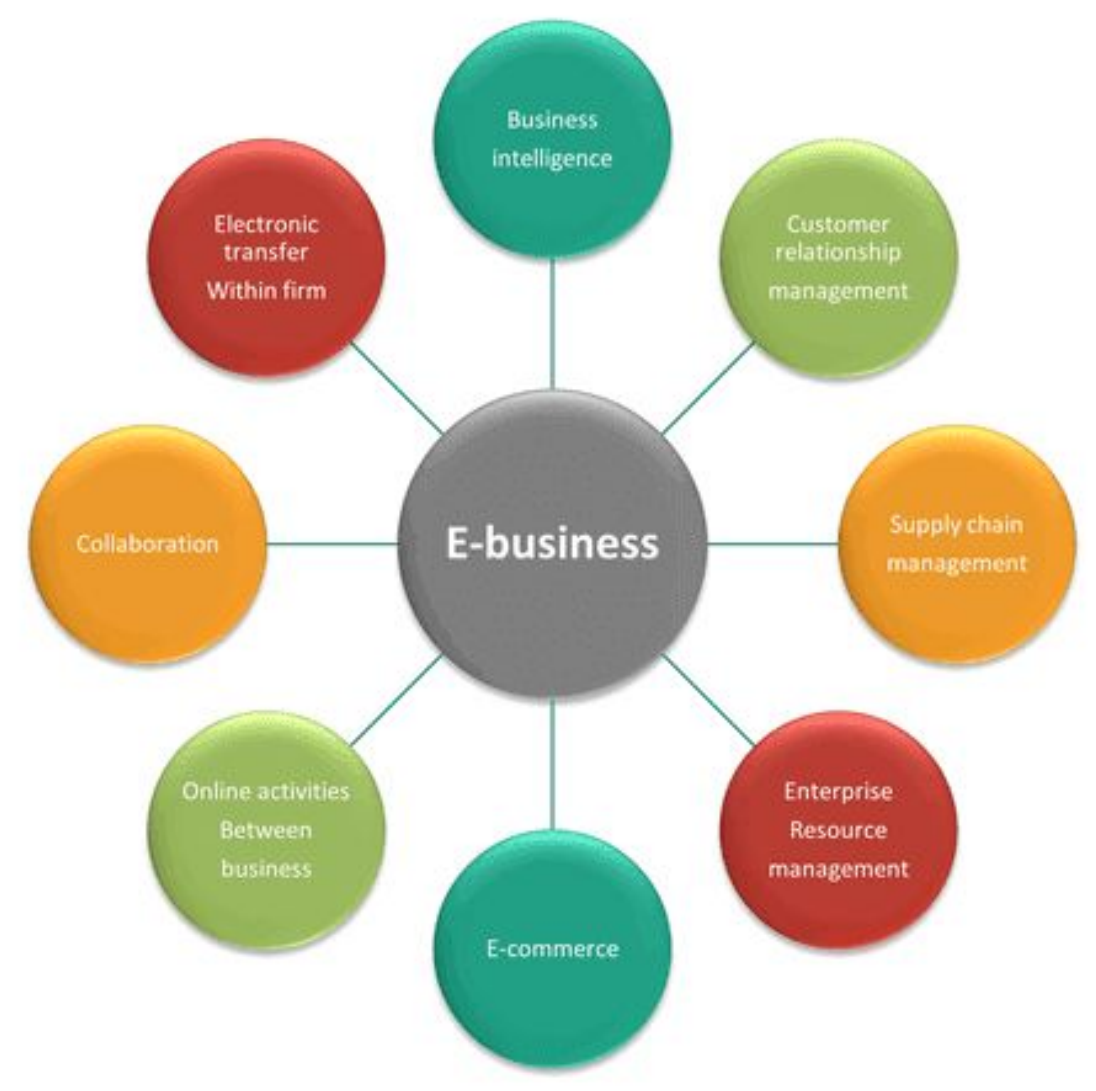




\section{Journal of Student Research}

Figure 2. E-commerce and online marketing strategies

According to Abdulmalik Abdulkarim al Balushi CEO of Oman post company. there are plans to have eleven distribution centers across Oman to cater to order items from their areas, we need to improve e-commerce delivery and a system to know the customer exactly location is. It's all about taking an opportunity for an offer that's is lower than the market.

E-Commerce Business play value role in economic and national development. It is working effectively including planning, controlling, promotion and distribution of different goods and services. Business transaction interacts electronically rather than a physical exchange or direct physical content. E-Commerce is the way of the use of electronic communications and numerical info processing technology in a business transactions to create, transform and create relationships among the organization and between organizations and individuals.

E-Commerce is a way to establishing business over the internet. It has a huge impact on communication, service, finance, trade and holds promises in education, health, transportation, and government. Moreover, E-Commerce, in general, provide opportunities for making the business going fast, reduce cost, grasp new customers and develop new business replicas and markets in the business organization. In general impact, electronic markets digitalization crops will influence material movements. there are respective terms of commerce and business. Commerce is representing as the concept of trade, exchange of produce on large scale by different countries using the electronic mediums. E-businesss the process involved leading and operation of the business that are electronic in nature, direct business activities like, marketing, sales, human resource accounting HRM but also indirect activities such as, re-engineering and change management, but effect of the efficiently of business process and activities (Jaffe . D, 2008) .

\section{Analysis}

It is about a new main concept that includes all previse business management and economic main point. like E-Business and E-Commerce impact in many parts of business and punishments management studies. Management Information Systems which include analysis, design, and implement of e-businesss systems within an organization and problem of front end and back end system. Human Resource Management ( HRM) is complex of online interaction, home working like working on a project by project basics replacing employees. Finance and Accounting are online banking, will contain a complex of transaction costs, accounting where imperceptible possessions and human capital must be palpably valued information-based budget.

Economies are the impact of E-commerce on native and worldwide economics understanding the concept of numerical and data related to the financial and whose appropriate concept. Production and Operation Management, it takes seconds to deliver digitalized products and service electronically. Predication is integrated with finance marketing and another financial system. Marketing is the problem of the online announcements, promotion plans, and customer behavior and culture. Computer Disciplines is the development of a new kind of network and figuring technology and linguistic to sports e-commerce and e-business as an example connecting the front and back-office bequest system with the web. Business Law and Ethics, it is the harvest of the result of global virtual market issues such as copyright laws, privacy, of customer info.

Figure 3. Online/ Digital marketing processes

Having a look at Istizada report online website, Oman providing chances for stat up and low budget companies to quickly and easily gain a foothold in online marketing, in addition to already well established organizations. With a rapidly growing and modernizing population, $78.5 \%$ of which regularly uses the internet and searches a goole, once gives shrewdness marketers the potential of 


\section{Journal of Student Research}

Fourth Middle East College Student Research Conference, Muscat, Sultanate of Oman

rapid profit and growth. This marketing profit will outline the context of Omani market, analysis of Ecommerce, CEO, PPC advertising and social media in Oman and ways in which Oman can benefit and challenge digital marketers.

Basic overview of saltant of Oman by understanding the context of the country in which your marketing campaigns are based is a crucial component of targeting your desired population. Here's some main info about to get you started.

Oman has a population of 3.92 million over $40 \%$ which is composed of immigrants rendering to the data from the UN. This small country economy is mostly counting on oil resources which are currently from 46\% part of Oman's government revenue ( Gop) ( Cheffy. D, 2012).

\section{Discussion}

According to the traditional retail by ( Khurana. A, 2019). There are some Advantages of Ecommerce for business and customers that help the failure to develop. Graphical limitations, any physical store connected with graphical location that you can serve. By e-commerce website everything is your playground. Ecommerce become easy with mobile devices has solved every residual limitation of geography. Provide new customers with search tool discernibility. Retails by branding and relation to these drivers, online trade is also driven by traffic from search engine results and land on an e-commerce website that they never caught of. Inferior charges, positive of ecommerce is lower costs about of these based on customer's inform of detached value. Moreover, some ways cost lower with e-commerce. Like, advertising and marketing, social media circulation are some of the promotion stations that can be cost-efficiently. Staffs are the automation of checkout, promoting, reimbursement, account running and real plantation, an e-commerce merchant does not need a protuberant bodily location.

Moreover, locate the product fast, Reject travel time and cost, offer comparison shopping, Enable deals, agreements, vouchers, and group purchasing. also, providing plentiful info, create beleaguered communication by using the information that the customer provides in the registration form by placing sweets on the customer's lap. As an example, if you searching about the product on Amazon.com, will also show a similar list of items and the website may email you about related items. The business still opens all the time and Makes marketplaces for items Position, what's willy mater is from where the customers searching for products in the searching machine. This is the wonder of e-commerce.

Online marketing depending on the consumer strategy in marketing, which runs by three main ideas. Knowing how customer behaves effects on marketing its very important to understand the three behavior factors psychological, personal and social.

Psychological, every day the customer is affected by many problems that are different to there thinking strategy presumption of need situation, they need to understand and learn data and individual behavior, everyone will respond on marketing messages based on their perception and behavior. This is a good factor must marketers take into account.

The personal elements, this factor should be specific persons and not related to any groups of people, personality may involve how persons make decagons are also influenced by age, gender, background, culture, and act. As an example, an older person will likely display different customer altitudes than a younger people, meaning they will choose goods differently and spend their money on products that may not interest the younger group.

Social element has a unique effect on customer performance as they majestically effect on how people affect by marketing messages and make canes expressions. As an example, how using a wellknown representative can affect purchasers (Pring. T, 2016). 


\section{Conclusion}

The terms of E-commercee and E-businesss is sometimes used internet unsteadily. When an electronic medium is used every day actively, it may e used as E-business. When the commercial transaction takes over an electronic network, then it is become as e-commerce. E-business is a very broad main topic that involves a business industry to use an electronic average to carry out all particular or overall commercial events .E-business work with reacting, training employees and shearing any internal info to agreement business procedure. E-commerce info and computing technologies are used with inter and intra corporate transactions and in business to customer dealings. E-business and E-commercee booth will know as business processes as well as tech substructure of databases, request servers, security tools, systems organization, and bequest schemes. Online marketing is an investment in your business. Interactively guide simply will ask you questions to make sure you're equipped to invest your advertising dollars astutely and reach your marketing aims (William . P, Jr, Joseph . C, E. Jerome. M, 2017).

\section{References}

Khurana. A (2019). Advantages of E-Commerce Business, small Business, Nov, 20, [link] www.thebalancesmb.com

Nair. V, Nair. V, (2017), Simply Oman, Is E-commercee coming of age in Oman, Nov.29, www.omanobserver.om)

Subramanian. R (2016). Product Marketing Associate at Zoho Corporation Oct, 14 ).

Kenneth C. Langdon, Jane P. Laudon , (2011), Management information systems: managing the digital firm, Hardcover, Ninth Edition, 736 pages, Published March 1st

Kenneth C. Laudon, Carol Traver,( 2006), E-Commerce: Business, Technology, Society, Hardcover, Third Edition, 879 pages, Published March 1st

Jaffe. D, (2008), The Best Service is No Service: How to Liberate Your Customers from Customer Service, Keep Them Happy, and Control Costs, pub, March 21

Walker. J (2014), Launch: An Internet Millionaire's Secret Formula To Sell Almost Anything Online, Build A Business You Love, And Live The Life Of Your Dreams, June 24

Cheffy. D (2012), E-Business and E-Commerce Management: Strategy, Implementation, and Practice, pub, Aug 21

prinSg.T(2016), Power of Connected Marketing: 3 of the World's Leading Marketing Experts reveal they're proven Online, Offline \& In-store Strategies to grow your Business and Dominate your marketplace, pub, April 23

William. P, Jr, Joseph. C, E. Jerome. M (2017), Essentials of Marketing: A Marketing Strategy Planning Approach, Pub, March 19th 